\title{
Inclusão, acessibilidade e permanência: direitos de estudantes surdos à educação superior ${ }^{1}$
}

\section{Inclusion, accessibility and permanence: the right to higher education for people with hearing impairment}

\author{
Sandra Eli Sartoreto de Oliveira Martins* \\ Carlo José Napolitano**
}

\begin{abstract}
RESUMO
O aumento de matrícula de estudantes surdos no ensino superior tem se constituído como fato recorrente na atualidade. $\mathrm{O}$ texto em questão problematizará as conquistas e os avanços de universitários surdos, usuários da Língua Brasileira de Sinais (Libras), nessa etapa de sua educação. Em decorrência da multiplicidade de fatores e da consolidação da educação inclusiva, abordará ainda aspectos legais e judiciais que favorecem a acessibilidade deste público às instituições de ensino superior (IES) no país. As considerações procuraram desmistificar as ações equivocadas sobre os direitos sociais e os individuais deste grupo que, a exemplo das ações afirmativas, devem primar pela prevalência da igualdade de oportunidades e de justiça, como valores supremos de uma sociedade fraterna, pluralista e inclusiva, no âmbito da Educação.

Palavras-chave: Políticas públicas. Educação superior. Inclusão. Surdo. Libras.
\end{abstract}

DOI: $10.1590 / 0104-4060.51043$

1 Acessibilidade no Ensino Superior (Processo n ${ }^{\circ}$ 23038.002628/2013-4. Observatório da Educação/Coordenação de Aperfeiçoamento de Pessoal de Nível Superior - Obeduc/Capes).

* Universidade Estadual Paulista (UNESP). Programa de Pós-Graduação em Educação. Marília, São Paulo, Brasil. Av. Hygino Muzzi Filho, nº 737. Campus Universitário. CEP 17525-900. E-mail: sandreli@marilia.unesp.br

** Universidade Estadual Paulista (UNESP). Programa de Pós-Graduação em Comunicação da Faculdade de Arquitetura, Artes e Comunicação. Bauru, São Paulo, Brasil. Av. Eng. Luiz Edmundo Carrijo Coube, nº 14-01. Vargem Limpa. CEP: 17033-360. E-mail: carlonapolitano@faac.unesp.br 


\begin{abstract}
The increasing number of students with hearing impairment enrolled in higher education has become a recurring fact nowadays. This paper will discuss the achievements and advances of deaf students who use the Brazilian Sign Language (Libras) in higher education. Due to the multiplicity of factors and the consolidation of the inclusive education, this text will also discuss legal and judicial aspects that enable the access and permanence of these individuals in the university. Considerations presented in the text aim to demystify misleading actions on social and individual rights of this group, that, like the affirmative actions, should strive for the prevalence of equal opportunity and justice as supreme values of a fraternal, pluralistic and inclusive society in an educational context.
\end{abstract}

Keywords: Public policies. Higher education. Inclusion. Deafness. Libras.

\title{
Introdução
}

Dados do Censo demográfico de 2010 indicam que 45,6 milhões de pessoas se declararam com alguma deficiência na faixa etária economicamente ativa da sociedade brasileira, compreendida por pessoas de 14 a 64 anos de idade, segmento populacional apto a ingressar no ensino superior. Do montante mencionado, quase $1 / 4$ da população $(23,9 \%)$ apresenta deficiência a partir de graus de severidade do acometimento nas seguintes tipologias: visual, auditiva, motora e mental/intelectual. O Censo constata ainda que a prevalência dos tipos de deficiências com maior incidência estava associada à deficiência visual $(18,6 \%)$, em primeiro lugar, seguida da deficiência motora $(7 \%)$, deficiência auditiva $(5,1 \%)$ e deficiência intelectual (1,4\%). (IBGE, 2012).

Ao se referir sobre o público mencionado, o Instituto Nacional de Estudos e Pesquisas, por meio dos dados divulgados na Sinopse Estatística da Educação Superior (INEP, 2013), indica que 7.305.977 de estudantes brasileiros efetuaram matrículas em instituições de ensino superior ${ }^{2}$ (IES) em 2012. Desta amostra total, 29.034 declararam apresentar alguma necessidade especial constitutiva do público-alvo da Educação Especial. Conforme indicado na Política da Educação

2 De acordo com as normativas e diretrizes políticas do Ministério da Educação e do Instituto Anísio Teixeira (INEP, 2013), denomina-se instituições de ensino superior as universidades, os centros universitários, os centros federais de educação tecnológica, as faculdades integradas, as faculdades, as faculdades tecnológicas, os institutos ou escolas superiores. 
Especial na Perspectiva da Educação Inclusiva (2007), compreende-se como público-alvo da Educação Especial

[...] àqueles que têm impedimentos de longo prazo, de natureza física, mental, intelectual ou sensorial, que em interação com diversas barreiras podem ter restringida sua participação plena e efetiva na escola e na sociedade. [...]. Na perspectiva da educação inclusiva, a educação especial passa a constituir a proposta pedagógica da escola, definindo como seu público-alvo os alunos com deficiência, transtornos globais de desenvolvimento e altas habilidades/superdotação (BRASIL, 2007, 2015).

Das 29.034 matrículas efetivadas, $19.628(67,6 \%)$ estavam presentes na rede privada, contrapondo-se às $9.406(32,4 \%)$ das universidades públicas. A amostra constatada dos dados quantitativos revela que 3.943 eram cegos, 6.955 deficientes visuais, 1.488 surdos, 7.850 deficientes físicos, 7.037 deficientes auditivos, 151 surdocegos, 393 deficientes múltiplos, 566 deficientes intelectuais, 118 autistas, 57 com Síndrome de Asperger, 24 com Síndrome de Rett, 68 com Transtorno Desintegrativo da infância e 1.087 com Superdotação.

Embora a predominância classificatória da tipologia da deficiência seja um critério de identificação para o Censo (IBGE, 2012), considera-se oportuno mencionar que este estudo adotará outra forma de designação para este grupo que se encontra em situação de deficiência, em função das restrições aos bens materiais e valores produzidos pela humanidade em diferentes âmbitos - social, cultural, econômico. Visto que situa o sujeito em interação com distintos modos e barreiras definidas pelas características anatomofisiológicas, determinado por um corpo ineficiente, impedido de usufruir de forma autônoma/independente dos conhecimentos produzidos em sociedade, situação criticada e explorada no texto, mais adiante.

Posto isso, é possível afirmar que o aumento de matrícula do público, mencionado nos cursos de graduação das instituições de ensino superior, seja atribuído ao desenvolvimento de políticas públicas inclusivas relacionadas especificamente ao ensino superior. Entre elas, o Plano de Reestruturação e Expansão das Universidades Federais (REUNI), projeto que subsidia a redução das taxas de evasão, aproveitamento de vagas ociosas, otimização da mobilidade estudantil, reorganização curricular, diversificação da oferta de cursos de graduação, ampliação de políticas de inclusão e assistência estudantil. O Programa Universidade para Todos (PROUNI), que facilita a ocupação de vagas a estudantes de baixa renda em instituições privada e orienta a institucionalização 
da Política de Acessibilidade nas instituições federais de educação superior ${ }^{3}$ (IFES). Além do Programa de Inclusão no Ensino Superior (INCLUIR), que, amparado em dispositivos legais e em orientações de organismos internacionais, tem como meta a democratização do ensino visando grupos populacionais em situações de vulnerabilidade social, com a finalidade de assegurar o direito da pessoa com deficiência à educação superior (SECADI, 2013).

Políticas públicas podem ser compreendidas como "um emaranhado de normas, processos e arranjos institucionais mediados pelo direito", sendo este um elemento constitutivo, intrínseco a tais políticas. Nesses termos, o direito é "objetivo, arranjo institucional, vocalizador de demandas ou ferramentas de políticas públicas" (COUTINHO, 2013, p. 182). Em outros termos, "o direito permeia intensamente as políticas públicas em todas as suas fases ou ciclos: na identificação da agenda para enfrentá-lo, na concepção de propostas, na implementação de ações e na análise e avaliação dos programas" (COUTINHO, 2013, p. 193).

Impulsionado por mudanças que objetivam erradicar o segregacionismo e a discriminação deste segmento populacional, o reconhecimento às diferenças tem se constituído como um princípio fundamental de convivência e respeito humano nos espaços educacionais. Na educação superior não deve ser diferente!

Considerando este princípio fundamental, de acordo com Napolitano (2010), a atual Constituição brasileira estipula inúmeras finalidades, objetivos e valores que o Estado e a sociedade brasileira devem concretizar, ou pelo menos almejar, sendo um desses valores o respeito às diferenças, o combate às formas de discriminação e à inclusão social, como será tratado neste texto.

Em termos filosóficos, os ideais de inclusão social se afastam das concepções reducionistas de homem e de aprendizagem balizadas por fatores que prescrevem a hereditariedade e ambiente, imprescindíveis ao desenvolvimento humano, mas se aproximam do materialismo dialético, que considera o psiquismo do homem fruto das relações do indivíduo com a sociedade. Esta concepção considera as estruturas da consciência e do comportamento humano decorrente do processo de apropriação pelo homem da experiência histórica e cultural (LEONTIEV, 1978; VYGOTSKY, 1993). O organismo e o meio exercem influência recíproca, em que o biológico e o social não estão dissociados, mas se constituem como tal através das suas interações sociais, sendo que um indivíduo pode se transformar e ser transformado pelas relações produzidas em determinada cultura.

3 Mais informações a respeito do REUNI e do PROUNI podem ser vistos no texto de Sobrinho (2010). 
Ao se referir sobre o impacto do materialismo dialético na educação, a partir das contribuições dos constructos da psicologia histórico-cultural, Tuleski (2008, p. 119) ressalta que o desenvolvimento do comportamento do homem [...] "só pode ser entendido em suas características e atitudes no interior das relações de produção que estabelece em sociedade".

Tendo em vista as ponderações iniciais, sobretudo a defesa de que todos têm o direto de frequentar a universidade, inclusive em situação de deficiência, este artigo problematizará as conquistas e avanços da comunidade surda brasileira, usuária da Língua Brasileira de Sinais (Libras), na educação superior. Em decorrência da multiplicidade de fatores que envolvem a inclusão deste público na universidade (SECADI, 2013), neste artigo se abordará questões legais e judiciais que favorecem o seu acesso e permanência na educação superior, bem como situações fáticas que, de alguma forma, inibem ou até mesmo impedem de se alcançar esse objetivo.

\section{Educação bilíngue e universidade: perspectivas atuais}

Problematizar a educação dos surdos, no contexto universitário, remete a compreender a surdez como diferença, que, por definição, é concebida por representações em matizes de significações linguísticas, políticas e culturais. Tal premissa tem sido fundamentada na concepção da deficiência enquanto fenômeno histórico-social.

A surdez nesta perspectiva deve se afastar da ideia de condição ou de um atributo a um ouvido deficitário e/ou de deficiência - definida como insuficiência e/ou incapacidade para aprender por outras vias sensoriais, que não o da audição - representa um desafio aos que circulam pelos espaços educacionais. Entretanto, reconhecê-la como diferença implica a luta pela consolidação da educação dos surdos nesta etapa de educação (BOSCO; MARTINS; GIROTO, 2012).

Balizados pelos estudos de Gesser, Nuernberg e Toneli (2013), pode-se afirmar que, para além das funções de funcionamento anatomofisiológico diferenciado da maioria das pessoas que se encontram na condição mencionada, o contexto tem sido mais ou menos restritivo ao seu desenvolvimento para uma vida independente. Tais restrições remetem às inúmeras barreiras presentes na sociedade em diferentes âmbitos: arquitetônico, metodológico, comunicacional, atitudinal, digital, entre outros. Assumir essa posição, para situar a ideia de deficiência, requer deixar de concebê-la apenas como um problema de ordem biológica e de saúde, que necessita de cuidados médicos para adotar uma 
dimensão mais macrossocial, na qual o sujeito está submetido às condições econômica, social e cultural do país em que vive.

Os autores continuam a explicitar que a deficiência vista desta perspectiva desloca e/ou opõe-se a visão ideológica do inesperado, da exceção, da "tragédia humana" para situar-se nas discussões gerais dos discursos políticos, sociais, educacionais que envolvem a diversidade humana. Nesse modelo, a surdez pode ser reconhecida por um modo de vida singular, de possibilidades dignas da condição humana - com culturas e comunidades específicas que se identificam com um cidadão e que, acima de tudo, requerem políticas sociais e formas equivalentes de suporte para alcançar uma vida independente em sociedade.

No caso de estudantes surdos, o direito ao acesso à educação superior pressupõe reconhecer as necessidades de políticas públicas dirigidas ao reconhecimento da Libras, como primeira língua, e a Língua Portuguesa (oral e/ou escrita), como a segunda, em diferentes contextos educacionais (ensino comum ou especial), conforme descrito pela Lei $\mathrm{n}^{\circ} 10.436 / 02$ e regulamentada pelo Decreto $n^{0} 5.626 / 05$, denominada de educação bilíngue. A esse respeito, o Relatório da Política Linguística de Educação Bilíngue - Libras e Língua Portuguesa (SECADI, 2014) - aponta que a Convenção Internacional sobre os Direitos das Pessoas com Deficiência e a $24^{a}$ Declaração Universal dos Direitos Linguísticos - promovidas pela UNESCO, em Barcelona, em 1996 - enfatizam que

[...] Todas as comunidades linguísticas têm direito a decidir qual deve ser o grau de presença da sua língua, como língua veicular e como objeto de estudo, em todos os níveis de ensino no interior do seu território: pré-escolar, primário, secundário, técnico e profissional, universitário e formação de adultos. (SECADI, 2014, p. 4).

Dito de outro modo, a educação bilíngue passa, então, a ser desejável como resultado das conquistas mais recentes da comunidade surda que valoriza a presença do profissional tradutor-intérprete de Libras/Português também neste nível de ensino. Segundo o mesmo documento, em seu art. 24, devem ser garantidas aos surdos:

[...] a) Facilitação do aprendizado da língua de sinais e promoção da identidade linguística da comunidade surda; e b) Garantia de que a educação de pessoas, inclusive crianças cegas, surdocegas e surdas, seja ministrada nas línguas e nos modos e meios de comunicação mais adequados às 
pessoas e em ambientes que favoreçam ao máximo seu desenvolvimento acadêmico e social. (SECADI, 2014, p. 4).

Essa proposta educacional envolve a criação de ambientes linguísticos para a apropriação da Libras como primeira língua (L1) por estudantes surdos, no tempo de desenvolvimento linguístico convencional e semelhante ao de estudantes ouvintes, e a aquisição do português como segunda língua (L2). A educação bilíngue se constitui de modo regular em que a Libras integra [...] "as línguas envolvidas em seu currículo e não faz parte do atendimento educacional especializado, ocorrendo em sua maioria em escola para surdos" (SECADI, 2014, p. 4). Torna-se necessária a garantia da apropriação das línguas envolvidas no currículo escolar, como condição para o desenvolvimento educacional do surdo, com vistas à constituição da sua identidade linguística e cultural em Libras. Assim, a educação básica, na perspectiva bilíngue, deve ser garantida de modo análogo às crianças ouvintes e falantes do português, independente do lócus em que for desenvolvida. A educação para surdos deve ocorrer em escola ou classes de instrução bilíngue, nos seguintes termos do Relatório da Política Linguística de Educação Bilíngue - Libras e Língua Portuguesa (SECADI, 2014, p. 4, 20):

[...] educação em escola para surdos em tempo integral. Os municípios que não comportem escolas bilíngues de surdos devem garantir educação bilíngue em classes bilíngues nas escolas comuns (que não são escolas bilíngues de surdos). [...] classes bilíngues no ensino comum em municípios que demonstrar baixa demanda de surdos, quando não houver escolas polos multimunicipais na região.

No que diz respeito à perspectiva de oferta da educação bilíngue no contexto inclusivo, o documento (SECADI, 2014) refere ainda que a inserção do surdo na sala de aula comum deve ocorrer apenas a partir do primeiro ano do segundo ciclo do ensino fundamental, incluindo ensino médio e ensino superior. Nestes níveis de ensino, é desejável que o estudante surdo possa dialogar e interagir na sua primeira língua, Libras, por meio da presença de profissionais intérpretes (Libras/Português), devendo a sua formação ocorrer no sistema regular de ensino.

Abandonar a perspectiva clínica da surdez para concebê-la como uma diferença linguística, ideológica e cultural no cotidiano do trabalho pedagógico, também na educação superior, implicará reconhecer que tais pressupostos constituem a base de processos educativos e do desenvolvimento acadêmico dos 
surdos (SKLIAR, 1998; LEITE; MARTINS, 2012). Superar as desigualdades que impedem e/ou dificultam o acesso e a permanência desse público nas universidades têm se constituído um desafio para os profissionais que atuam nesta modalidade de ensino. Por fim, pode-se afirmar que a surdez não inferioriza o sujeito, mas dá pistas singulares sobre os modos como ele se apropria da cultura humana e, em certa medida, apreende o mundo pelas experiências visuais mediadas pela Libras.

Retomar políticas públicas que considerem os aspectos aqui descritos, sobre a educação bilíngue para os surdos e a organização desta nas IES, constitui-se o foco deste estudo. Assim, analisar os obstáculos que impedem e/ou dificultam o acesso e a participação desse público na educação superior tem sido considerado como meio pelo qual a sociedade, em parceria com a comunidade surda, revisita seus direitos em prol do acesso à formação desse segmento populacional, nesta etapa de ensino.

\section{Prescritivos legais: do acesso e a formação de estudantes surdos na universidade}

Buscar a democratização do acesso e a garantia de permanência dos estudantes em situação de deficiência na educação superior, bem como a qualidade científica e social desta educação têm sido recorrentes nas políticas educacionais.

Sobrinho, ao tecer considerações sobre a democratização da educação superior no Brasil, aponta que a qualidade deste nível de educação está comprometida por significados marcadamente operacionais e instrumentais, muito mais que sociais e voltados ao bem comum. É dever do Estado ofertá-la para todos com vistas à consolidação de sujeitos sociais, e "[...] não somente para parcela privilegiada da sociedade e para o fortalecimento do individualismo, [...] Quando não compreendida como bem público, a educação atende prioritariamente ao indivíduo e a seus interesses exclusivos" (SOBRINHO, 2010, p. 1225).

Ao professá-la como um bem comum a todos, Sobrinho lembra que a democratização não se limita à ampliação de oportunidades de acesso e criação de mais vagas na educação superior. Sabe-se que a expansão das matrículas e a inclusão social de jovens tradicionalmente desassistidos no âmbito educacional, somadas à discriminação e ao preconceito, atribuídos a este grupo populacional, entre os quais se encontram as pessoas em situação de deficiência, de forma igualitária, requerem atendimento educacional especializado (AEE) para cursar esta etapa de ensino (BRASIL, 2011; INEP, 2013). É imprescindível que lhes 
sejam assegurados também os meios de permanência sustentável; isto é, serviços ou recursos especializados destinados à permanência e à conclusão dos seus estudos na universidade, conforme recomendado pela Política da Educação Especial na Perspectiva da Educação Inclusiva (BRASIL, 2007).

Assim, acesso e permanência, como aspectos essenciais do processo mais amplo de democratização, restringem a sua importância a uma das faces da questão, o que, para Sobrinho (2010, p. 1226), deixa de retratar temas do valor público, da qualidade social e da pertinência. Numa análise mais pontual sobre as políticas de educação superior, refere que esta [...] "deve ser vista e organizada como um sistema articulado. Vale dizer que o tempo da educação é um tempo total, permanente, contínuo, pois a formação humana é um processo jamais concluído".

O inacabamento é da essência humana, ainda que o discurso social tenda a impingi-lo às classes sociais de baixa renda, fazendo crer que os pobres são imperfeitos, em oposição a uma falsa e ilusória completude dos indivíduos pertencentes aos segmentos ricos e poderosos. [...] A exclusão escolar, em qualquer etapa, é privação de algumas bases cognitivas, sociais e axiológicas que todo indivíduo necessita para edificar uma existência humanamente significativa na sociedade contemporânea. (SOBRINHO, 2010, p. 1226).

Diante do exposto, pensar a universidade comprometida com a educação de todos, em especial dos surdos usuários da Libras, deverá assumir mecanismos de acessibilidade no exame vestibular conforme previsto no Decreto $\mathrm{n}^{0} 3.298$ (BRASIL, 1999), Portaria n 3.284 (BRASIL, 2003), Circular n 277 (BRASIL, 1996), Lei n ${ }^{\circ} 13.146$ - Lei Brasileira de Inclusão (BRASIL, 2015), entre outras.

Entre as recomendações mais imediatas, tais normativas convergem quando indicam ajustes necessários à organização do exame vestibular, sob três aspectos: a) na elaboração do edital de seleção, para que possa expressar, com clareza, os recursos que poderão ser utilizados pelo vestibulando no momento da prova, bem como os critérios de correção a serem adotados pela comissão do vestibular; b) no momento dos exames vestibulares, quando serão providenciadas salas especiais para cada tipo de deficiência e a forma adequada de obtenção de respostas pelo vestibulando; c) no momento da correção das provas, sendo necessário considerar as diferenças específicas inerentes a cada deficiência, para que o domínio do conhecimento seja aferido por meio de critérios compatíveis com as características especiais desses alunos. Em se tratando da pessoa com 
surdez, a correção da Língua Portuguesa na forma oral/escrita deverá ser coerente com o aprendizado do uso desta, como segunda língua (L2), e valorizar as características semânticas em torno das singularidades dadas pelo uso da Libras, como primeira língua (L1).

Aos candidatos surdos, a Circular $\mathrm{n}^{\circ} 277$ ainda prescreve [...] "a presença de intérprete de Língua de Sinais no processo de avaliação" (BRASIL, 1996). A esse respeito, cabe às instituições responsáveis pela organização dos exames desenvolverem ações que possibilitem a flexibilização dos serviços educacionais e da infraestrutura, bem como a capacitação de recursos humanos, de modo a melhor atender às necessidades especiais dos candidatos com deficiência durante o exame, como também após seu ingresso à universidade.

A despeito das normativas mencionadas, lamentavelmente verifica-se que nem todas as universidades estão preparadas para o acolhimento de estudantes surdos. Como exemplo de desrespeito, no exame vestibular de 2015, tais normativas foram descumpridas a 13 candidatos surdos inscritos, pela Fundação para o Vestibular da Universidade Estadual Paulista - VUNESP (UNESP, 2014a) e Resolução Unesp 68, que estabelece normas para o Concurso Vestibular Unesp 2015 e dá outras providências (UNESP, 2014b); sendo garantidos a eles apenas a presença do fiscal/intérprete na prova, com base na apresentação do laudo médico da perda de audição, como condição no ato da inscrição.

Após a conclusão da primeira etapa do processo seletivo, ao ser questionado sobre o apoio recebido, um candidato declarou que o "intérprete se restringiu em traduzir as informações iniciais da realização da prova" (UNESP, 2015, p. $3)^{4}$. "Nos momentos quando solicitado a esclarecer termos específicos de uma língua para outra, demonstrou dificuldades e/ou desconhecimento sobre como fazer tais ajustes". Tal conduta foi relatada por outro candidato surdo, para quem "a prova não foi fácil, pois a intérprete poucas vezes conseguia esclarecer os significados das palavras por sinônimos em Língua de Sinais. [...] A intérprete não sabia vários sinais e/ou termos em português para traduzir para a Libras" (UNESP, 2015, p. 3). Tais depoimentos evidenciam situações que pouco contribuíram para o êxito no exame. Surdos querem a prova em Libras conforme a Recomendação $n^{\circ}$ 001, do Conselho Nacional dos Direitos da Pessoa com Deficiência (CONADE), da Secretaria dos Direitos Humanos, publicada em 15 de julho de 2010. Esse documento tem sido considerado uma referência legal

4 Os dados foram retirados do relatório do projeto de Extensão intitulado "ACESSIBILIDADE E EDUCAÇÃO SUPERIOR: proposta de orientação a estudantes surdos sobre o exame vestibular", cadastrado no Sistema de Extensão Universitária, da Pró-Reitoria de Extensão (PROEX) da Universidade Estadual Paulista (UNESP, 2015). 
para que os editais de concursos sejam disponibilizados em Libras e operacionalizados no formato bilíngue.

Segundo a Portaria $\mathrm{n}^{\mathrm{o}} 3.284 / 03$, art. $1^{\mathrm{o}}$, alínea b, e o Decreto $\mathrm{n}^{\mathrm{0}} 5.626 / 05$, art. $14, \S 1^{\circ}$, III, alínea b, é responsabilidade das instituições de ensino prover a contratação do tradutor e intérprete de Libras/Língua Portuguesa. Tal medida tem por finalidade amenizar as barreiras comunicacionais e de aprendizagem dos surdos na apropriação dos conteúdos curriculares, favorecendo a sua interação com os ouvintes.

Atualmente tem-se conhecimento de que a Universidade Federal de Santa Catarina (UFSC) vem atendendo a legislação vigente com a finalidade de eliminar as barreiras no acesso ao vestibular (INEP, 2013; COPERVE, 2015) ${ }^{5}$ e na contratação de profissionais para a referida função, garantindo o pleno direito de participação dos surdos na educação superior.

Entretanto, apesar do reconhecimento de tais esforços, sabe-se que algumas IES estão sanando a oferta de apoios na forma de bolsas de estudos e de monitoria aos estudantes universitários com conhecimento em Libras para o exercício desta função aos surdos. Esse fato pode ser constatado pela abertura de Inquérito Civil Público, pela $9^{\circ}$ Promotoria de Justiça de Marília (IC ${ }^{\circ}$ 14.0716.0006488/2014), após representação de aluna surda que questionou junto ao Ministério Público o não oferecimento de tradutor-intérprete em Libras (TILS). Em substituição à contratação de professor TILS, as instituições de ensino superior providenciaram a contratação de bolsistas para o exercício dessa função (SÃO PAULO, 2014a). Tal providência é considerada aqui uma medida meramente paliativa, pois não atende o determinado na legislação, na qual estabelece políticas públicas institucionais que visam à inclusão de alunos surdos na educação superior. A insuficiência de tal medida foi reconhecida recentemente pelo Tribunal de Justiça de São Paulo (TJSP), que considerou a oferta de bolsista em substituição à contratação de TILS uma "Atividade exercida de maneira precária, devido a essa circunstância” (SÃO PAULO, 2015).

Contrária ao posicionamento adotado pelas IES, tal prerrogativa tem se constituído como tratativa para orientar a educação bilíngue de estudantes surdos em diferentes etapas da educação, a exemplo dos editais de concursos públicos para contratação do profissional tradutor-intérprete de Língua Brasileira de Sinais - Libras/Língua Portuguesa, conforme descrito no Edital nº 08/2012, do

5 A Universidade Federal de Santa Catarina, por meio da Comissão Permanente do Vestibular (COPERVE) do Concurso Vestibular UFSC/2015, orienta e esclarece as normas para o exame vestibular em atendimento aos dispositivos legais mencionados neste texto. Também disponibiliza uma versão do EDITAL 05/COPERVE/2014 em Libras (COPERVE, 2015). Mais informações podem ser obtidas pelo site http://www.vestibular2015.ufsc.br/editais-e-resolucoes/. 
Instituto Federal de Educação, Ciência e Tecnologia do Maranhão, campus São Luís Monte Castelo (IFTM, 2012), e na Instrução n ${ }^{\circ}$ 003/2012, da Secretaria de Estado da Educação do Paraná, da Superintendência da Educação (SEED/SUED, 2012), que estabelece normas para contratação e atuação desse profissional nos estabelecimentos de ensino da rede pública estadual.

Diante do exposto, é notório observar que os que deveriam se responsabilizar por defender os direitos dos cidadãos, por desconhecimento de causa em decorrência das especificidades que envolvem a temática abordada - as políticas linguísticas em favor do cumprimento da educação bilíngue para surdos universitários - são os mesmos que colocam em risco os direitos conquistados por este mesmo grupo, quando lhes são negados a contratação de profissionais qualificados para a prática da interpretação de Libras/Português, nas ações ofertadas pelas IES, condição necessária à formação do surdo, nesta etapa de ensino.

Destarte, por conta dos motivos explicitados, somados aos entraves administrativos/burocráticos na promoção de ações afirmativas, capazes de acionar dispositivos imediatos para a contratação do intérprete de Libras, que só pode ocorrer por meio de concursos públicos previstos no organograma institucional das IES, o contexto atual tem dificultado e postergado a oferta de apoios para cursar a universidade. Embora tal prática esteja sendo executada por IES, conforme mencionado acima e apurado no referido Inquérito Civil Público e reconhecido pelo TJSP, há que se considerar estratégias e medidas de formalização de concursos destinados à contratação desses profissionais, em consonância com a Lei ${ }^{\circ} 12.319$, de setembro de 2010, que regulamenta a profissão de TILS, fato que se constituirá o foco das ponderações a seguir.

\section{Direito, políticas públicas de inclusão e judicialização da política}

As normativas citadas, até o presente momento, objetivam a concretização dos preceitos constitucionais acerca da inclusão social das pessoas com deficiência, em especial, a inclusão via educação. Nesse sentido, o texto constitucional de 1988 previu regras no intuito de integrar a pessoa com deficiência ao ambiente escolar como forma de socialização (NAPOLITANO, 2010).

Dispõe o texto constitucional, no art. 205, que o acesso à educação é um direito de todos e um dever do Estado e da família. O acesso deverá ser promovido e incentivado com a colaboração da sociedade, visando ao pleno desenvolvimento da pessoa, seu preparo para o exercício da cidadania e sua 
qualificação para o trabalho, garantindo o atendimento educacional especializado, preferencialmente na rede regular de ensino (BRASIL, 1988, art. 208, III).

Por atendimento especializado, pode-se inferir o emprego de suportes pedagógicos para que o aluno em situação de deficiência possa se beneficiar do ensino regular, tais como: uso de estratégias de ensino específicas e professor com formação adequada; adaptação de materiais ou recursos didático-pedagógicos; agrupamentos diferenciados em sala de aula; ajustes na temporalidade do ensino; adaptações ou adequações curriculares; bem como o auxílio de tradutor-intérprete de Libras.

Os termos da Constituição brasileira, com nítido teor social e econômico, configuram uma de suas peculiaridades. O Brasil tem por tradição adotar textos constitucionais descritivos e de regulação da vida em sociedade, e a Constituição de 1988 não ficou longe dessas referências. Por esses motivos, ela é considerada por Coutinho (2013, p. 190) como sendo "progressista, generosa e transformativa", e, não por acaso, foi "apelidada de 'constituição cidadã", bem como "ela contém normas ditas 'programáticas' - isto é, normas que preveem objetivos a serem alcançados por meio de políticas públicas e comandos que explicitam valores a serem perseguidos pelo legislador infraconstitucional, juízes e administradores públicos". Ao inserir nas normas constitucionais conteúdos de políticas públicas governamentais, de natureza econômica, de atribuição do papel do Estado na condução da economia, a nova sistemática constitucional trouxe, segundo Arantes e Couto (2004), fortes implicações no modus operandi do sistema político brasileiro e no sistema de justiça.

Ao constitucionalizar esses assuntos relacionados à atividade econômica e social, como foi o caso da inclusão de estudantes em situação de deficiência na educação superior, o constituinte obrigou os governantes eleitos a efetivarem modificações constitucionais e legais antes de colocarem em prática os seus programas básicos de governo relacionados à economia. Esses programas podem estar traduzidos em emendas à constituição e em alterações legislativas infraconstitucionais que, potencialmente, podem passar a ser também objeto de análise por parte do Judiciário brasileiro.

O fato de a Constituição de 1988 constitucionalizar assuntos de natureza econômica, segundo Arantes e Couto (2004), reduziria a margem de manobra decisória dos atores políticos, ou seja, do Legislativo e do Executivo. A competição continuaria sendo viabilizada por meio de eleições, entretanto, ficaria restrita por imposições constitucionais aos governos eleitos. Ademais, a constitucionalização da ordem econômica abriu a possibilidade, no Brasil, país adepto ao controle de constitucionalidade das leis, de o Judiciário ser acionado para manifestar-se quanto à constitucionalidade ou não de algum programa, 
meta ou objetivo de governo que deverão estar vinculados por uma emenda constitucional ou a uma lei infraconstitucional.

Na mesma linha de raciocínio é a opinião de Grau (2003), pois a legalização ou constitucionalização das políticas públicas induz à profusão de regras jurídicas, alterando a própria lógica do direito, que passa a regulamentar situações conjunturais ao invés de ordenar a estrutura do Estado, fato que acarreta maior flexibilidade e possibilidade de revisão das normas jurídicas. Nesse sentido, pode-se afirmar que o Estado não mais interviria na sociedade como o produtor do direito, mas que "passa a desenvolver novas formas de atuação, para o quê faz uso do direito positivo como instrumento de implementação de políticas públicas" (GRAU, 2003, p. 26).

A revisão das normas apontadas por Grau (2003) pode se dar através de um novo governo eleito ao propor alterações constitucionais e legais, ou mesmo através do Poder Judiciário - órgão responsável por verificar a validade ou não de uma lei -, seja referente a questões estruturais de um Estado, seja referente a assuntos conjunturais, tais como as políticas públicas de inclusão social. Essa peculiaridade do constitucionalismo brasileiro de elevação das políticas públicas a direito constitucional, por si só, alarga sobremaneira o leque de ações do Poder Judiciário, pois este será, inevitavelmente, acionado para dirimir conflitos, tendo em vista a aplicação ou não de uma política pública. A possibilidade de o Judiciário atuar, controlando e fiscalizando políticas públicas, está relacionada com a temática da judicialização da política, termo compreendido como a possibilidade de revisão, no Judiciário, de uma decisão tomada pelos poderes políticos tendo por fundamento o ordenamento constitucional (CARVALHO, 2004), o que possibilita ao Judiciário intervir ativamente nas decisões legislativas e executivas.

No que tange especificamente à questão tratada neste artigo, ou seja, a disponibilização de intérprete de Libras para estudantes surdos, a justiça brasileira já foi acionada para dirimir conflitos relacionados à precariedade de políticas públicas sobre essa questão. A esse respeito, segundo a Lei $\mathrm{n}^{0} 12.319$, de setembro de 2010, o TILS deve demonstrar formação adequada e ser capaz de mediar a interação discursiva entre surdos e ouvintes, nas duas línguas - na L1 e na L2, ambas de forma simultânea ou consecutiva, demonstrando proficiência em tradução e interpretação dessas línguas, conforme previsto pelo Decreto $\mathrm{n}^{\mathrm{o}}$ 5.626/06, Capítulo IV, art. 14:

$\S 1^{\circ}$. Para garantir o atendimento educacional especializado e o acesso previsto no caput, as instituições federais de ensino devem:

I - promover cursos de formação de professores para: 
a) o ensino e uso da Libras;

b) a tradução e interpretação de Libras - Língua Portuguesa; e

c) o ensino da Língua Portuguesa, como segunda língua para pessoas surdas $[\ldots]$.

Como exemplo do cumprimento desta afirmativa, pode ser mencionada a recente decisão do Tribunal de Justiça de São Paulo (TJSP), de agosto de 2014, proferida na Apelação nº 0011339-89.2013.8.26.0554, da Comarca de Santo André, em que é apelante a Fazenda do Estado de São Paulo e apelado estudante surdo da rede estadual de ensino. O TJSP reconheceu o direito deste de ter auxílio de professor intérprete de Libras, conforme ementa do acórdão que segue, em resumo:

deficiente auditivo, que pretende o recebimento de auxílio de professor intérprete dos sinais em Língua Brasileira de Sinais (Libras), a fim de possibilitar igualdade de condições para seu acesso e permanência na escola pública Estadual. Garantia à Educação que impõe este dever constitucional e legal. (SÃO PAULO, 2014b).

$\mathrm{Na}$ fundamentação do Acórdão, de relatoria do Desembargador Rebouças de Carvalho, ficou registrado que o aluno, desde 2012, tentava, sem sucesso, o atendimento especializado garantido por lei. O pedido judicial estava baseado na intenção de manter a "igualdade de condições para o acesso e permanência na escola", como também a "garantia de padrão de qualidade do ensino". Ademais, argumentou o aluno que "deveres constitucionais não podem se convolar em instrumentos inatingíveis, como se fossem molduras que servem apenas para o fim de embelezamento dos discursos políticos". (SÃO PAULO, 2014b). Na decisão, o relator da Apelação destaca ainda que existem outros precedentes do próprio Tribunal acerca dessa questão e menciona diversas apelações como exemplo.

Verifica-se também que o Supremo Tribunal Federal (STF) já se manifestou sobre a temática. No Agravo Regimental no Recurso Extraordinário com Agravo $n^{\circ} 860.979$, a Segunda Turma do STF reconheceu o acerto de decisão do Tribunal de Justiça do Distrito Federal (TJDF) que determinou ao governo do Distrito Federal a contratação de professor especializado em Libras para atender aos estudantes surdos, conforme ementa que segue, em resumo: 
Educação de deficientes auditivos. Professores especializados em Libras. Constitucionalidade e convencionalidade das políticas públicas de inserção dos portadores de necessidades especiais na sociedade. Precedentes. (BRASIL, 2015).

No acórdão, lavrado pelo Ministro Gilmar Mendes, ficou registrada a existência de inúmeros precedentes do próprio STF sobre a inclusão social de pessoas em situação de deficiência. Também ficou consignado que a inclusão no sistema regular de ensino está prevista na Constituição Federal e deve ser implementada via políticas públicas, como é o caso da oferta de TILS para os estudantes surdos.

Muito embora a decisão do TJSP tenha por base um estudante do ensino fundamental, nada impede que essa interpretação e aplicação do direito, por analogia, possa ser estendida também aos surdos no ensino superior, seja para garantir o acesso nos exames vestibulares, seja para garantir a permanência desses na educação superior.

\section{Considerações finais}

Nas últimas duas décadas, o governo brasileiro tem assumido a política educacional inclusiva (BRASIL, 2007, 2015), provocando transformações na organização e funcionamento da educação a grupos populacionais em situações de vulnerabilidade social e em condições anatomofisiológicas, psicossociais, linguísticas e culturais. Diferentes da maioria dos jovens que se encontram em idade para cursar a educação superior, a exemplo da situação de estudantes surdos, foco deste texto.

Em atendimento às políticas mencionadas, as IES buscam institucionalizar ações e estratégias afirmativas que visem à eliminação de obstáculos que impedem e dificultam a participação efetiva desse grupo nesta etapa de formação acadêmica. Entre as conquistas mais recentes, destaca-se a promulgação de diferentes normativas que têm por finalidade assegurar o acesso e a permanência deste grupo à universidade (PROGRAMA INCLUIR13; Decreto ${ }^{\circ}{ }^{3.298 / 1999 ;}$ Portaria $n^{\circ}$ 3.284/2003; Circular $n^{\circ}$ 277/1996; Decreto $n^{\circ}$ 5.626/2005; Lei ${ }^{\circ}$ 12.319/2010; Atendimento Diferenciado para o ENEM (INEP, 2012); Lei ${ }^{\circ}$ 13.146/2015 - Lei Brasileira de Inclusão (BRASIL, 2015).

Embora seja possível identificar a formulação de políticas e as ações afirmativas que visem formas de apoios a este segmento populacional, inúmeros 
são os desafios para que as pessoas surdas possam acessar e concluir os estudos nas IES. Destarte, conceber a universidade como um espaço democrático capaz de conceber o desenvolvimento da consciência e do comportamento humano, como decorrente do processo de apropriação pela experiência histórica e cultural (LEONTIEV, 1978) produzida pelo homem. A educação assume papel principal nesse processo, o que exigirá reconhecer que os surdos se caracterizaram como grupo linguístico minoritário e se constituem nas interações sociais, sendo capazes de transformar-se e ser transformado nas relações produzidas na e pela educação superior. Assim posto, tal afirmativa remeterá considerar providências, apoios e serviços educacionais especializados com vistas à acessibilidade dos exames de vestibular e, em direção ao ingresso à universidade, priorizar a contratação de profissionais qualificados para a função de tradutor-intérprete de Libras/Português - condição indispensável ao desenvolvimento deste grupo na universidade.

Assumir o impacto dos preceitos e prescritivos legais relatados ao longo do texto, entre outros aspectos, tem por finalidade evitar interpretação e aplicação equivocadas da Lei $n^{0} 10.436 / 2002$ e do Decreto $n^{0} 5.626 / 2005$, que orientam, em igual medida, a formulação de dispositivos institucionais para o acesso aos exames vestibulares e a formação bilíngue de estudantes surdos (SECADI, 2014) na educação superior.

\section{REFERÊNCIAS}

ARANTES, R. B.; COUTO, C. G. Constituição, governo e democracia no Brasil. In: ENCONTRO ANUAL DAANPOCS, 28, 2004, Caxambu. Anais... Caxambu: Anpocs, 2004.

BOSCO, D. C.; MARTINS, S. E. O. S.; GIROTO, C. R. M. Alunos com surdez e o processo de inclusão: uma análise dos discursos sobre língua de sinais. Revista Ibero-Americana de Estudos em Educação, v. 7, p. 7-98, 2012. Disponível em: <http://www. unesp.br/seer.fclar.unesp.br>. Acesso em: 05 jun. 2015.

BRASIL. Constituição da República Federativa do Brasil. Brasília: Senado Federal, 1988.

BRASIL. Ministério da Educação. Aviso Circular n ${ }^{\circ} 277$, de 08 de maio de 1996. Disponível em: $<$ http://portal.mec.gov.br/arquivos/pdf/aviso_circular277.pdf $>$. Acesso em: 05 mar. 2015.

BRASIL. Decreto $n^{\circ} 3.298$, de 20 de dezembro de 1999. Disponível em: <http://www. planalto.gov.br/ccivil_03/decreto/d3298.htm>. Acesso em: 06 jun. 2015. 
BRASIL. Lei n ${ }^{\circ} 10.436$, de 24 de abril de 2002. Dispõe sobre a Língua Brasileira de Sinais - Libras e dá outras providências. Diário Oficial da União: República Federativa do Brasil: Poder Legislativo, Brasília, DF, 24 abril 2002. Disponível em: $<$ http:// www.jusbrasil.com.br/legislacao/99492/lei-de-libras-lei-10436-02\#art0>. Acesso em: 02 maio 2014.

BRASIL. Ministério da Educação. Portaria n 3.284, de 7 de novembro de 2003.

BRASIL. Decreto $n^{\circ}$ 5.626, de 22 de dezembro de 2005. Regulamenta a Lei $\mathrm{n}^{\circ} 10.436$, de 24 de abril de 2002, que dispõe sobre a Língua Brasileira de Sinais - Libras e, o art. 18 da Lei no 10.098, de 19 de dezembro de 2000. Disponível em: <http://www.planalto. gov.br/ccivil_03/_ato2004-2006/2005/decreto/d5626.htm>. Acesso em: 04 abr. 2015.

BRASIL. Política Nacional de Educação Especial na Perspectiva da Educação Inclusiva. Brasília, 2007. Disponível em: $<$ http://peei.mec.gov.br/arquivos/politica_nacional_educacao_especial.pdf>.Acesso em: 11 jun. 2015.

BRASIL. Decreto n ${ }^{\circ} 7.611$, de 17 de novembro de 2011. Dispõe sobre a educação especial, o atendimento educacional especializado e dá outras providências. Diário Oficial da União: República Federativa do Brasil: Poder legislativo, Brasília, DF, 17 nov. 2011. Disponível em: <http://www.planalto.gov.br/ccivil_03/_Ato2011-2014/2011/Decreto/ D7611.htm>. Acesso em: 12 jan. 2015.

BRASIL. Lei $n^{\circ}$ 13.146, de 6 de julho de 2015. Institui a Lei Brasileira de Inclusão da Pessoa com Deficiência. Estatuto da Pessoa com Deficiência. Brasília, 2015.

BRASIL. Supremo Tribunal Federal. Agravo Regimental no Recurso Extraordinário com Agravo $n^{\text {o }}$ 860.979. 2015. Disponível em: <http:/www.jusbrasil.com.br/diarios/ documentos/187109772/andamento-do-processo-n-860979-do-dia-06-05-2015-do-stf $>$. Acesso em: 05 jun. 2015.

CARVALHO, E. R. de. A judicialização da política no Brasil: apontamentos para uma nova abordagem. Rio de Janeiro: ABCP, 2004.

CONADE. Secretaria dos Direitos Humanos. Recomendação $n^{\circ}$ 001, de 15 de julho de 2010. Conselho Nacional dos Direitos da Pessoa com Deficiência - CONADE. 2010. Disponível em: $<$ http://www.csjonline.web.br.com/PDF/Recomendacao_Concurso_Publico_Surdos.pdf>.Acesso em: 04 jun. 2015.

COPERVE. Comissão Permanente do Vestibular da Universidade Federal de Santa Catarina. Edital de Concurso Vestibular UFSC/2015. Orienta e esclarece as normas para o exame vestibular em atendimento aos dispositivos legais mencionados neste texto. Disponível em: < http://www.vestibular2015.ufsc.br/editais-e-resolucoes/>. Acesso em: 10 jun. 2015.

COUTINHO, D. R. O direito nas políticas públicas. In: MARQUES, E.; FARIA, C. A. P. de (orgs.). A politica pública como campo multidisciplinar. São Paulo: Ed. UNESP; Rio de Janeiro: Ed. Fiocruz, 2013. p. 181-200. 
GESSER M.; NUERNBERG, A. H.; TONELI, M. J. F. constituindo-se sujeito na intersecção gênero e deficiência: relato de pesquisa. Psicologia em Estudo, Maringá, v. 18, n. 3, p. 419-429, jul./set. 2013.

GRAU, E. R. O direito posto e o direito pressuposto. 5. ed. São Paulo: Malheiros, 2003.

IBGE. Ministério do Planejamento, Orçamento e Gestão Instituto Brasileiro de Geografia e Estatística - IBGE. Censo Demográfico 2010. Características gerais da população, religião e pessoas com deficiência, 2012.

IFTM. Instituto Federal de Educação, Ciência e Tecnologia do Maranhão. Ministério da Educação. Edital $n^{\circ}$ 08, de 11 de março de 2012. Institui o edital público para contratação de tradutor e intérprete de Língua Brasileira de Sinais - Libras/Língua Portuguesa, conforme descrito no do Instituto Federal de Educação, Ciência e Tecnologia do Maranhão, campus São Luís, Monte Castelo, 2012. Disponível em: <file://C:/Users/ Sandra/Downloads/editaln\%C2\%BA08drgmc_int\%C3\%A9rpretedelibras.pdf $>$. Acesso em: 24 jun. 2015.

INEP. Ministério da Educação. Diretoria de Avaliação da Educação Básica. $O$ atendimento diferenciado no ENEM. 2012. Disponível em: < http://download.inep.gov.br/ educacao_basica/enem/nota_tecnica/2012/atendimento_diferenciado_enem_2012.pdf $>$. Acesso em: 14 fev. 2015.

INEP. Ministério da Educação. Censo da educação superior: questionário - aluno, Brasília: Instituto Nacional de Estudos e Pesquisas Educacionais Anísio Teixeira, 2013. Disponível em: <http://portal.inep.gov.br/web/censo-da-educacao-superior/questionarios-e-manuais $>$. Acesso em: 14 fev. 2015.

LEITE, L. P.; MARTINS, S. E. S. de O. Fundamentos e estratégias inclusivas: respostas às diferenças na escola. Marília: Cultura Acadêmica; Oficina Universitária, 2012.

LEONTIEV, A. O desenvolvimento do psiquismo. São Paulo: Moraes, 1978.

NAPOLITANO, C. J. Direito fundamental à proteção e à integração social da pessoa com deficiência à luz do texto constitucional. In: CAPELLINI, V. L. M. F.; RODRIGUES, O. M. P. R. (Org.). Formação de professores na perspectiva da educação inclusiva: marcos históricos, conceituais, legais e éticos da educação inclusiva. Vol. 2. Bauru: Unesp/FC/ MEC, 2010. p. 81-109.

SÃO PAULO. Inquérito Civil Público no 14.0716.0006488/2014. $9^{\text {a }}$ Promotoria de Justiça de Marília. Ministério Público do Estado de São Paulo, 2014a.

SÃO PAULO. Apelação $n^{\circ}$ 0011339-89.2013.8.26.0554. Tribunal de Justiça de São Paulo, 2014b.

SÃO PAULO. Apelação $n^{\circ}$ 0019661-96.2012.8.26.0566. Tribunal de Justiça de São Paulo, 2015.

SECADI. Documento orientador programa incluir: acessibilidade na educação superior. SECADI/SESU, 2013. 
SECADI. Relatório sobre a Política Linguística de Educação Bilíngue - Língua Brasileira de Sinais e Lingua Portuguesa. Grupo de Trabalho, designado pelas Portarias $n^{\circ} 1.060 / 2013$ e no 91/2013 do MEC/SECADI. Brasília, 2014. Disponível em: <http:// www.bibliotecadigital.unicamp.br/document/?down=56513>. Acesso em: 11 jun. 2015.

SEED/SUED. Secretaria de estado da educação do Paraná, da Superintendência da Educação. Instrução $n^{o}$ 003/2012. Estabelece normas para contratação e atuação desse profissional nos estabelecimentos de ensino da rede pública estadual. 2012. Disponível em: <file://C:/Users/Sandra/Downloads/instrucao0032012libras.pdf>Acesso em: 24 jun. 2014.

SKLIAR, C. Educação e exclusão: abordagem socioantropológica em educação especial. Porto Alegre: Mediação, 1998.

SOBRINHO, J. D. Democratização, qualidade e crise na educação superior: faces da exclusão e limites da inclusão. Educ. Soc., Campinas, v. 31, n. 113, p. 1223-1245, out./ dez. 2010.

TULESKI, S.C. Vygotski: a construção de uma psicologia marxista. 2. Ed. Maringá: Eduem, 2008.

UNESP. Manual do Candidato: Vestibular 2015 VUNESP. 2014a. Disponível em: $<$ http:// www.vunesp.com.br/vnsp1406/VNSP1406_306_020601.pdf>. Acesso em: 04 jun. 2015.

UNESP. Resolução Unesp $n^{\circ}$ 68, de 22 de agosto de 2014. Estabelece normas para o Concurso Vestibular Unesp 2015 e dá outras providências. Publicada no DOE, 2014b. Disponível em: <http://www.vunesp.com.br/vnsp1406/VNSP1406_306_019061.pdf>. Acesso em: 04 jun. 2015.

UNESP. Pró-Reitoria de Extensão Universitária (PROEX). Acessibilidade e educação superior: proposta de orientação a estudantes surdos ao exame vestibular. 2015. Sistema de Extensão Universitária da Pró-Reitoria de Extensão da Universidade Estadual Paulista (Unesp), sob o Processo n ${ }^{\circ}$ 2076-2015.

VYGOTSKY, L. S. Problemas de psicología general. Madri: Visor, 1993 (Obras Escogidas, $\left.n^{\circ} 2\right)$.

Texto recebido em 05 de março de 2017. Texto aprovado em 31 de março de 2017. 